\title{
Altered Hepcidin Expression is Part of the Choroid Plexus Response to IL-6/Stat3 Signaling Pathway in Normal Aging Rats
}

\author{
Chongbin $L^{1,2^{*}}$, Rui $W^{1}$, Chunyan $W^{1}$, Chen HU1 and Qifeng $D^{1}$
}

${ }^{1}$ Department of Physiology, Huzhou Teachers College, Huzhou, Zhejiang Province, P. R. China

${ }^{2}$ Zhejiang Provincial Key Lab for Technology and Application of Model Organisms, Wenzhou Medical University, Wenzhou, Zhejiang Province, P. R. China

\begin{abstract}
Accumulating evidence has revealed that brain iron concentrations increase with aging, and the choroid plexus may be at the basis of iron-mediated toxicity and the increase in inflammation and oxidative stress that occurs with aging. However, nothing is known concerning the correlation between the IL-6/Stat3 signaling pathway and the levels of hepcidin expression at the choroid plexus (CP) in normal aging. The morphological modifications as a function of aging were investigated and the present study used quantitative real time PCR (qPCR) and western blotting (WB) to determine the alterations in specific mRNA and corresponding protein changes at the CP on aging at ages 3, 6, 9, 12, $15,18,21,24,27,30,33$ and $36 \mathrm{~m}$ Brown-Norway/Fischer (B-N/F) rats. Results showed that a striking deterioration of the CP epithelial cells, and results also firstly demonstrated that hepcidin expression at the choroid plexus increased with aging at the mRNA level and might cause corresponding changes in protein expression. These alterations in normal aging were in accordance with the expression and secretion of IL-6 and Stat3. Our data suggest that IL-6 regulate hepcidin expression at the choroid plexus, upon interaction with the cognate cellular receptor, and through the Stat3 signaling transduction pathway. The enhanced Stat3 signaling responsiveness to proinflammatory factors may impact on mechanisms of Alzheimer's disease.
\end{abstract}

Keywords: Aging; Choroid plexus; Hepcidin; IL-6; Stat3

\section{Introduction}

Advancing age is the major risk factor for many neurodegenerative disorders, including Alzheimer's disease (AD), a disease characterized by progressive memory and cognitive loss [1]. The predominant neuropathological hallmarks of $\mathrm{AD}$ are the accumulation of extracellular plaques containing insoluble amyloid- $\beta(\mathrm{A} \beta)$ peptide and intra-celluar neurofibrillary tangles [2]. Rapidly accumulating evidence indicates that nutritional iron enhances the neurotoxicity of $A \beta$ and each of the major protein participants in $\mathrm{AD}$ pathology has physiologically important interactions with transition metals [3,4]. Clearance of $A \beta$ from the brain occurs via active transport at the interfaces separating the central nervous system (CNS) from the peripheral circulation. The choroid plexus $(\mathrm{CP})$, where the blood-cerebrospinal fluid barrier (BCSFB) is located, is a polarized tissue, with the basolateral side of the choroidal epithelium facing the blood and the apical microvilli in direct contact with the cerebrospinal fluid (CSF). The tissue plays a wide range of roles in brain development, aging, nutrient transport, endocrine regulation, and pathogenesis of certain neurodegenerative disorders [5-7]. Additionally, recent studies strongly suggest that increased levels of peripheral inflammation can induce a response in the $\mathrm{CP}$ and influence iron metabolism $[8,9]$. Taking this feature of the $\mathrm{CP}$ epithelial cells into account, it is plausible that the $\mathrm{CP}$ is functioning in the brain as a regulator of iron metabolism when an inflammatory environment is established. It would be of great interest to know if that is the case in normal aging, since it is recognized that the levels of pro-inflammatory cytokines in the blood increase with age $[10,11]$, which can influence the secretion of iron-metabolism-related proteins, such as hepcidin (Hamp), by CP epithelial cells. A recent study has shown that increased peripheral markers of inflammation, measured in the blood of aged subjects, do not correlate with increased levels of blood circulating Hamp or low iron status in the brain [12]. However, nothing is known concerning the levels of Hamp in the brain cells or CSF of aged individuals. On the other hand, interleukin-6 (IL-6), which is able to trigger the cells signal transduction and activators of transcription 3 (Stat3) signaling pathway appears to be associated with old-age anemia and is over-expressed in the aged mouse brain in response to lipopolysaccharide (LPS) [10]. Since IL-6 is shown to participate in the regulation of the expression of Hamp, not only in the liver [13] but also in the CP [9] of adult mice, it remains to be assessed if the CP contributes to the level of IL- 6 in the aged brain. Moreover, the $\mathrm{CP}$ is able to up-regulate Stat 3 gene in conditions of peripheral inflammation, and these may contribute to regional regulation of iron in the CNS [9]. In normal aging, however, the pattern of expression of this gene by the CP is still unknown. We propose to study the agerelated alteration in IL-6/Stat3 pathway at the CP, which can elicit changes in the CP's capacity to regulate iron metabolism and to impact on the initiation and progression of brain pathology in $\mathrm{AD}$.

\section{Materials and Methods}

\section{Animals and tissue collection}

All the procedures were performed in accordance with ethical guidelines on the care and use of animals in laboratory research which were approved by the Institutional Animal Ethics Committee (IAEC). Male Brown-Norway/Fischer (B-N/F) rats $(n=96)$ were purchased from the Central Animal House of the College (Shanghai, China) on aging at ages $3,6,9,12,15,18,21,24,27,30,33$ and $36 \mathrm{~m}$. B-N/F rats are not as susceptible to cancer as the more inbred species and

*Corresponding author: Chongbin L, Department of Physiology, Huzhou Teachers College, Huzhou, Zhejiang Province 313000, P. R. China, Tel: 86-572259-2572; Fax: 86-572-232-1203; E-mail: liuchongbin1972@126.com

Received February 20, 2014; Accepted April 25, 2014; Published April 28, 2014

Citation: Chongbin L, Rui W, Chunyan W, Chen HU, Qifeng D (2014) Altered Hepcidin Expression is Part of the Choroid Plexus Response to IL-6/Stat3 Signaling Pathway in Normal Aging Rats. Bioenergetics 3: 115. doi:10.4172/21677662.1000115

Copyright: (c) 2014 Chongbin L, et al. This is an open-access article distributed under the terms of the Creative Commons Attribution License, which permits unrestricted use, distribution, and reproduction in any medium, provided the original author and source are credited. 
can live in excess of $36 \mathrm{~m}$. Rats were anesthetized by intraperitoneal injection of pentobarbital $(50 \mathrm{mg} / \mathrm{kg})$, and then perfused with $0.9 \mathrm{M}$ phosphate buffered saline (PBS), $\mathrm{pH} 7.4$, at $4^{\circ} \mathrm{C}$ via the left ventricle of the heart, using a peristaltic pump (Harvard Apparatus, Holliston, MA, USA). The top of the cranium was removed and the two lateral ventricle CPs were then dissected out under a microscope to ascertain cell types present. Tissues were immediately transferred to an ice-cold microcentrifuge tube containing RNAlater (Ambion, Austin, TX, USA) to limit degradation by endonucleases and then stored at $-80^{\circ} \mathrm{C}$ before quantitative real time PCR (qPCR) and western blotting (WB) analysis (All samples stored for an equal length of time before processing). For qPCR and WB, $\mathrm{n}=8$ (96 rats) were tested for each age group.

\section{Electron microscopy}

Samples of choroid plexus were fixed in $2.5 \%$ glutaraldehyde and $4 \%$ paraformaldehyde in $0.1 \mathrm{~mol} / \mathrm{L}$ cacodylate buffer ( $\mathrm{pH}$ 7.4). Specimens were post-fixed with $1 \%$ osmium tetroxide, dehydrated through ascending series of ethanol, and embedded in Epon. The serial semithin sections were stained with $1 \%$ toluidine blue and examined with a light microscope. The thin sections were viewed and photographed with a transmission electron microscope (Hitachi Ltd, Tokyo, Japan).

\section{Quantitative real time PCR}

Samples stored in RNA later were allowed to thaw and were rinsed with nuclease-free water before homogenizing in the lysis buffer provided in the Qiagen RNeasy kit (Qiagen, Valencia, CA, USA). This kit was used, according to the manufacturer's instructions, to extract the RNA. RNA concentrations were measured by a Nano Drop 1,000 spectrophotometer (Thermo Fisher Scientific, Wilmington, DE, USA) and stored at $-80^{\circ} \mathrm{C}$ until further use. $1 \mu \mathrm{g}$ of RNA was used with the Omniscript Reverse Transcription kit (Qiagen) to synthesize $20 \mu \mathrm{L}$ of cDNA and then CDNA was used for real time reverse transcription quantitative PCR (qPCR). For $\mathrm{qPCR}$, independent assays were performed using SYBR premix Ex Taq TM (Invitrogen, Carlsbad, CA, USA) with three biological replicates. Forward (F) and reverse (R) primers for each gene of interest were designed using Primer Premier software (PREMIER Biosoft International, Palo Alto, CA, USA). Primers used for the amplification of cDNA were summarized in Table 1. In each $25 \mu \mathrm{L}$ quantitative real time reaction using SYBR-ER master mix, $10 \mathrm{mM}$ primers and $1 \mu \mathrm{L}$ cDNA were implemented. Reactions were run in a Bio-Rad I Cycle system (Bio-Rad, Hercules, CA, USA) using Invitrogen's suggested protocol. The reactions were incubated at $72^{\circ} \mathrm{C}$ for $4 \mathrm{~min}, 4^{\circ} \mathrm{C}$ for $4 \mathrm{~min}$, followed by a 30 cycles of $4 \mathrm{~min}$ at $94^{\circ} \mathrm{C}, 4 \mathrm{~s}$ at $94^{\circ} \mathrm{C}, 4 \mathrm{~s}$ at $56^{\circ} \mathrm{C}$ and $25 \mathrm{~s}$ at $72^{\circ} \mathrm{C}$. Annealing temperatures (TA) varied and were specific for each primer set. The DNA band was visualized under UV light and was then extracted. The DNA was purified from each gel slice using Promega Wizard columns (Promega, Madison, WI, USA). All runs contained an inter run calibrator to account for any differences between runs. All data were normalized to the reference gene, $\beta$-actin, before statistical analysis was performed. The $2 \Delta \mathrm{CT}$ method was used to calculate the normalized expression of each gene for each sample [14] and the specific band of interest gene was confirmed by DNA gel electrophoresis [15].

\section{Western blotting analysis}

Samples were washed and homogenized in RIPA buffer containing $1 \%$ Triton X-100. After centrifugation at $10,000 \mathrm{~g}$ for 30 minutes at $4^{\circ} \mathrm{C}$, the supernatant was collected and protein concentration measured. Aliquots of the extract containing about $50 \mu \mathrm{g}$ of protein were separated by reducing $15 \%$ SDS-PAGE and electro blotted onto PVDF membranes for $45 \mathrm{~min}$ at room temperature. The membranes were blocked in 5\% non-fat milk containing $20 \mathrm{mM}$ Tris- $\mathrm{HCl}, \mathrm{pH} 7.6,137$ $\mathrm{mM} \mathrm{NaCl}, 0.1 \%$ Tween-20 (TBS-T) for 2 hours at room temperature, and then incubated with rabbit anti-mouse IL-6 (1: 5,000) (Alpha Diagnostic International) or rabbit anti-mouse phospho-stat3 $(1: 2,000)$ (Santa Cruz Biotech) for overnight at $4^{\circ} \mathrm{C}$. After washing with TBS-T three times, the membranes were incubated in anti-rabbit secondary antibody conjugated horseradish peroxide (1: 5,000) (Amersham, UK) for 2 hours at room temperature. Immunoreactive proteins were detected by using the enhanced chemiluminescence method (ECL kit; Amersham), and quantified by transmittance densitometry using volume integration with Gel-Pro software. To ensure even loading of the samples, the same membrane was probed with rabbit anti-human $\beta$-actin antibody (1: 5,000) (Sigma-Aldrich, St. Louis, MO, USA). The intensity of the specific bands was detected and analyzed by Odyssey infrared imaging system (Li-Cor). IL-6 or phospho-stat 3 protein levels in each specimen were normalized to $\beta$-actin.

\section{Statistical analysis}

For the qPCR analysis, Bio-Rad iQ5 Optical System software (BioRad, Hercules, CA, USA) using the $2 \Delta \mathrm{CT}$ method to calculate the normalized expression of each gene for each sample was employed [14]. Natural logarithm transformations of the data were used to correct for non-normality and inequality of variances, which was then confirmed by Shapiro-Wilk's and Levene's tests. Results were expressed as the mean \pm standard deviation. A single-factor ANOVA followed by Tukey's pairwise comparisons were used to analyze the data. All statistical analyses were conducted using the SPSS 13.0 software (IBM, Armonk, NY, USA), and differences were assumed to be significant if the probability $(\mathrm{P})$ value was $<0.05$.

\section{Results}

\section{The morphological modifications of the $\mathrm{CP}$ in normal aging rats}

The senescence of the $\mathrm{CP}$ was a gradual aging process. Aged $\mathrm{CP}$ epithelial cells presented a general atrophy (Figure 1C) when compared to the adult CP (Figure 1A). The epithelial cells displayed a decrease in height, total volume and length of the apical microvilli (Figure $1 \mathrm{~F}$ ) when compared to the adult CP (Figure 1D). The basement membrane, stroma, and blood vessel walls of the $\mathrm{CP}$ became thicker with age (Figure 1B and 1C) when compared to the adult CP (Figure 1A). The tight junctions (TJ) of neighboring $\mathrm{CP}$ epithelial cells degenerated in aged rats (Figure 1G) when compared to the adult CP (Figure 1E). There was a massive and extensive fibrosis observed in the central stroma and the surrounding of the $\mathrm{CP}$ (Figure $1 \mathrm{H}$ ), there were also responsible for the deficits in molecular exchanges between the $\mathrm{CP}$ and the CSF. Epithelial cells also acquired numerous lipofuscin vacuoles (Figure 1G) in normal aging animals. These modifications could alter choroid plexus functions, including synthesis, secretion and transport of proteins and other molecules.

\begin{tabular}{|l|l|}
\hline CDNA & Sequence \\
\hline \multirow{2}{*}{ IL-6 } & F: 5'- AGTTGCCTTCTTGGGACTGA-3' \\
& R: 5'- ACAGTGCATCATCGCTGTTC-3' \\
\hline \multirow{2}{*}{ Hepcidin } & F: 5'- CTGCCTGTCTCCTGCTTCTC-3' \\
& R: 5'- GGAAGTTGGTGTCTCGCTTC-3' \\
\hline \multirow{2}{*}{ P-Stat3 } & F: 5'- AGTTCTCGTCCACCACCAAG -3' \\
& R: 5'- CTAGCCAGACCCAGAACGAG -3' \\
\hline \multirow{2}{*}{-actin } & F: 5'-CACGATGGAGGGGCCGGACTCATC-3' \\
& R: 5'-TAAAGACCTCTATGCCAACACAGT-3' \\
\hline
\end{tabular}

Table 1: Rat gene-specific PCR primers 
Citation: Chongbin L, Rui W, Chunyan W, Chen HU, Qifeng D (2014) Altered Hepcidin Expression is Part of the Choroid Plexus Response to IL-6/ Stat3 Signaling Pathway in Normal Aging Rats. Bioenergetics 3: 115. doi:10.4172/2167-7662.1000115

Page 3 of 6
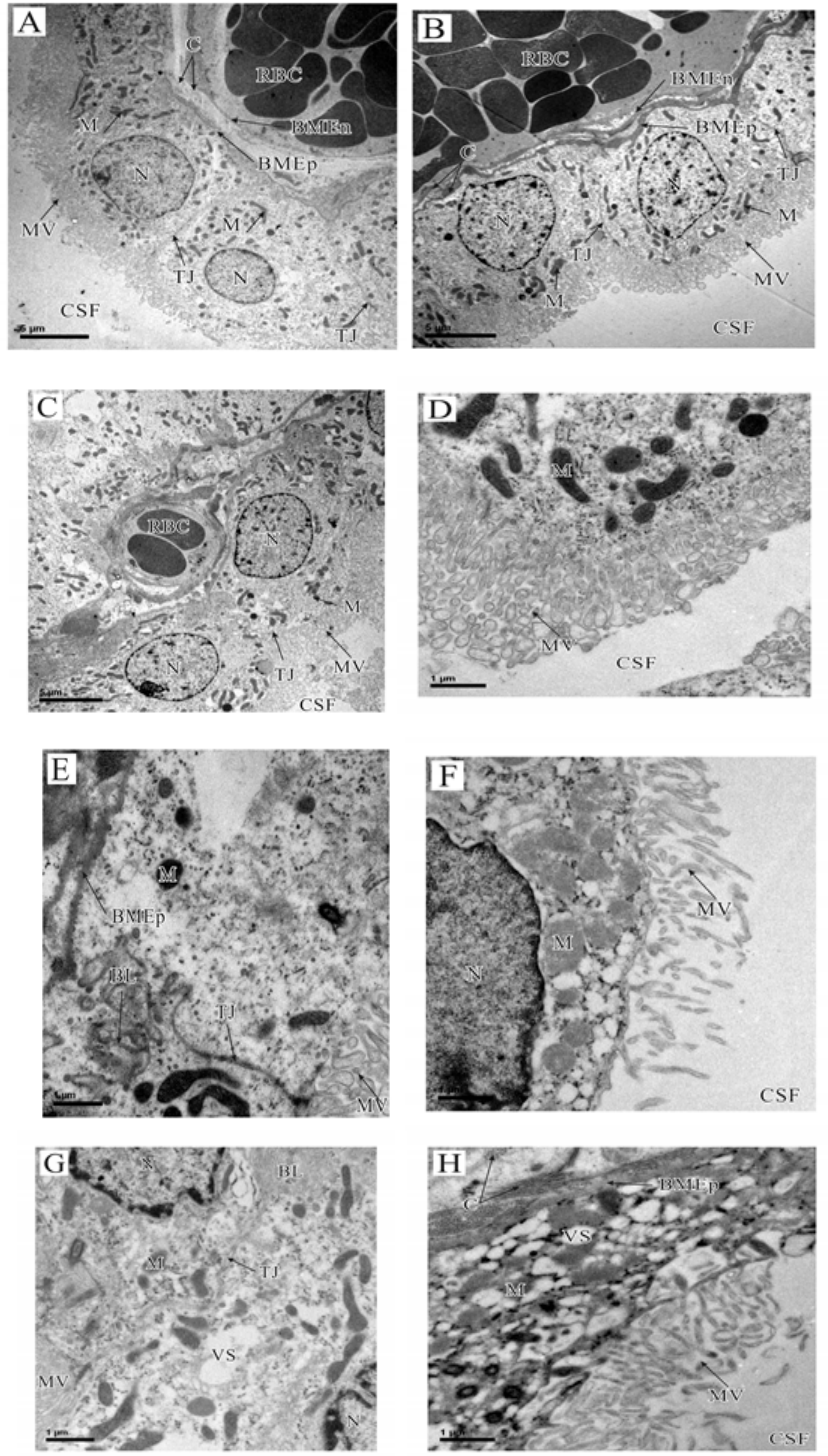

Figure 1: The morphological modifications of the $\mathrm{CP}$ in normal aging rats (A, D and E): components of adult rat lateral ventricle CP villus. Three epithelial cells comprise the apex of a villus projecting into CSF. Surfaces of epithelial cells are replete with microvilli (MV). Tight junctions (TJ) adjoin apical membranes of neighboring CP epithelial cells. Subjacent to epithelial cells is a sinusoidal blood vessel with several red cells (RBC). Clusters of collagen fibers (C) are seen in cross-section. Basement membranes (BMEp) lining the basal surfaces of CP epithelial cells are apparent as is the basemembrane (BMEn) of an endothelial cell lining the blood vessel. Numerous cytoplasmic organelles are visible in CP epithelial cells such as nuclei $(N)$ and mitochondria $(M)$. BL is the basal labyrinth. (B, C, F, G and H): The morphological modifications of the $\mathrm{CP}$ in aged CP epithelial cells. At the same time, epithlial cells acquire numerous vacuoles (VS) in aged rats.

\section{The expression of hepcidin $(\operatorname{Hamp})$ at the $\mathrm{CP}$ in normal aging rats}

The expression of the Hamp at the messenger RNA (mRNA) level with age was measured by quantitative real time PCR. Results showed that there was a mild increase in Hamp expression from 3 to $18 \mathrm{~m}$ group, followed by a significant increase to $36 \mathrm{~m}$ group (Figure
2A). One-way ANOVA showed an effect of age for the twelve tested age groups at the $\mathrm{P}<0.05$ level $[\mathrm{F}(11,49)=4.90, \mathrm{P}=0.021]$. Tukey's pairwise comparision revealed a significant difference in the mean natural log-transformed normalized expression of Hamp between 3 and $21 \mathrm{~m}, 3$ and $24 \mathrm{~m}, 3$ and $27 \mathrm{~m}, 3$ and $30 \mathrm{~m}, 3$ and $33 \mathrm{~m}, 3$ and $36 \mathrm{~m}$ rats $(\mathrm{P}<0.05$, Figure $2 \mathrm{~B})$. However, the $3,6,9,12,15$ and $18 \mathrm{~m}$ groups did not significantly differ from each other, or from 21 to $36 \mathrm{~m}$ groups (Figure 2B). Therefore, these results showed a continuous increase in the expression of Hamp at the CP epithelium after $21 \mathrm{~m}$ of age.

\section{The mRNA and protein expression of interleukin-6 (IL-6) at} the $\mathrm{CP}$ in normal aging rats

The expression of the IL- 6 at the mRNA level as a function of aging was measured by quantitative real time PCR at 3, 6, 9, 12, 15, 18, 21, $24,27,30,33$ and $36 \mathrm{~m}$ groups. Results showed that there was a mild increase in IL-6 expression from 3 to $21 \mathrm{~m}$ group (except to 6 and 15 $\mathrm{m}$ groups), followed by a significant increase to $30 \mathrm{~m}$ and then a mild decrease to $36 \mathrm{~m}$ group (Figure 3A). A one-way ANOVA showed an effect of age for the twelve tested age groups at the $\mathrm{P}<0.05$ level $[\mathrm{F}$ $(11,49)=2.47, \mathrm{P}=0.047]$. Tukey's pair wise comparison revealed a significant difference in the mean natural log-transformed normalized expression of IL- 6 between 6 and $24 \mathrm{~m}, 6$ and $27 \mathrm{~m}, 6$ and $30 \mathrm{~m}, 6$ and $33 \mathrm{~m}, 6$ and $36 \mathrm{~m}$ rats $(\mathrm{P}<0.05$, Figure $3 \mathrm{~B})$. However, the $3,9,12,15,18$, and $21 \mathrm{~m}$ groups did not significantly differ from each other, or from 24 to $36 \mathrm{~m}$ groups (Figure $3 \mathrm{~B}$ ).

The protein expression of the IL- 6 as a function of aging was also measured by western blotting. Results showed that there was a mild increase in IL-6 expression from 3 to $18 \mathrm{~m}$ group (except to 15 $\mathrm{m}$ group), followed by a significant increase to $33 \mathrm{~m}$ and then a mild decrease to $36 \mathrm{~m}$ group (Figure 4A). A one-way ANOVA showed an effect of age for the twelve tested age groups at the $\mathrm{P}<0.05$ level $[\mathrm{F}(11,49)=3.08, \mathrm{P}=0.036]$. However, the $3,6,9,12,15$, and $18 \mathrm{~m}$ groups did not significantly differ from each other, or from 21 to $36 \mathrm{~m}$ groups (Figure 4B). Therefore, CP IL-6 expression was either stable or increased with age.

\section{The mRNA and protein expression of phosphorylated signal transduction and activators of transcription 3 (P-Stat 3 ) at the $\mathrm{CP}$ in normal aging rats}

The expression of the P-Stat 3 at the mRNA level with respect to age was measured by quantitative real time PCR. Results showed that there was an increase in P-Stat 3 expression from 3 to $36 \mathrm{~m}$ group (except to 6, 24, 27 and $33 \mathrm{~m}$ groups) (Figure 5A). A one-way ANOVA showed an effect of age for the twelve tested age groups at the $\mathrm{P}<0.05$ level [F $(11,49)=4.33, \mathrm{P}=0.037]$. Tukey's pair wise comparison indicated a significant difference in the mean natural log-transformed normalized expression of P-Stat 3 between 6 and $21 \mathrm{~m}, 6$ and $30 \mathrm{~m}, 6$ and $33 \mathrm{~m}, 6$ and $36 \mathrm{~m}$ rats, and between 9 and $21 \mathrm{~m}, 9$ and $30 \mathrm{~m}, 9$ and $36 \mathrm{~m}$ rats $(\mathrm{P}<0.05$, Figure $5 \mathrm{~B})$. These results indicated that $P$-Stat 3 expression at the $\mathrm{CP}$ epithelium increased with age at the mRNA level. This effect became significant at $36 \mathrm{~m}$.

The protein expression of the P-Stat3 as a function of aging was also measured by western blotting. Results showed that there was a mild increase in P-Stat 3 expression from 3 to $21 \mathrm{~m}$ group (except to 9 , 15 , and $18 \mathrm{~m}$ groups), followed by a significant increase to $36 \mathrm{~m}$ group (except to $27 \mathrm{~m}$ group) (Figure 6A). A one-way ANOVA showed an effect of age for the twelve tested age groups at the $\mathrm{P}<0.05$ level [ $\mathrm{F}$ (11, $49)=4.25, \mathrm{P}=0.028]$. However, the $3,6,9,12,15$, and $18 \mathrm{~m}$ groups did not significantly differ from each other, or from 21 to $36 \mathrm{~m}$ groups (Figure 6B). 
Citation: Chongbin L, Rui W, Chunyan W, Chen HU, Qifeng D (2014) Altered Hepcidin Expression is Part of the Choroid Plexus Response to IL-6/ Stat3 Signaling Pathway in Normal Aging Rats. Bioenergetics 3: 115. doi:10.4172/2167-7662.1000115

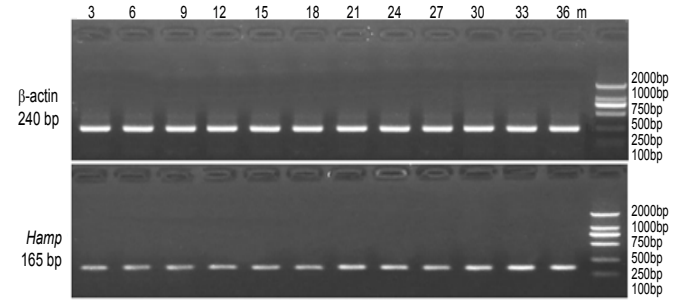

Figure 2A: Expression levels of hepcidin (Hamp) mRNA at the CP epithelium in normal aging rats

For real time reverse transcription quantitative PCR (qPCR), independent assays were performed using SYBR premix Ex TaqTM with three biological replicates. Gelred was added to the gel pre-run, the DNA band was visualized under UV light and was then extracted. It showed that there was a significant increase from 21 to $36 \mathrm{~m}$ group for the twelve aged groups, $\mathrm{n}=8$ for each age group.

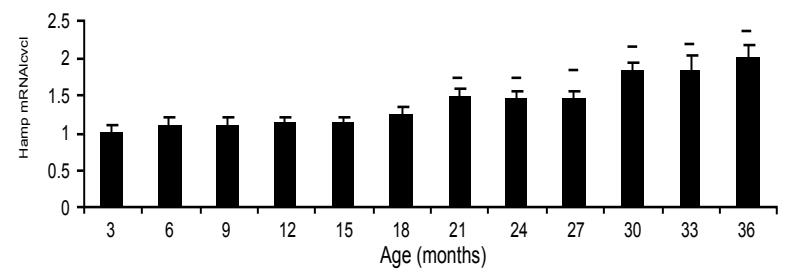

Figure 2B: The relative mRNA levels of hepcidin (Hamp) using real-time RT-PCR assay at the $\mathrm{CP}$ epithelium in normal aging rats.

The measured quantity of mRNA in each of treated samples was normalized using $C T$ values obtained for the $\beta$-actin mRNA amplifications running in the same plate. The data were the means \pm standard deviation of three sets of experiments.

Graph of the log-transformed normalized expression of Hamp with age, $n=8$ for each age group tested. One-way ANOVA revealed an effect of age for the twelve tested age groups at the ${ }^{*} P<0.05$ level.

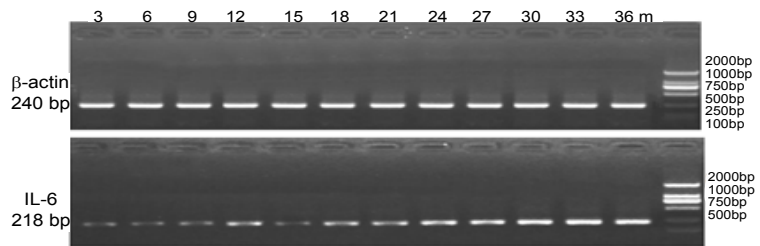

Figure 3A: mRNA expression levels of interleukin-6 (IL-6) at the CP epithelium in normal aging rats

For real time reverse transcription quantitative PCR (qPCR), independent assays were performed using SYBR premix Ex TaqTM with three biological replicates. Gelred was added to the gel pre-run, the DNA band was visualized under UV light and was then extracted. It showed that there was a significant increase from 24 to $30 \mathrm{~m}$ group for the twelve aged groups, $n=8$ for each age group.

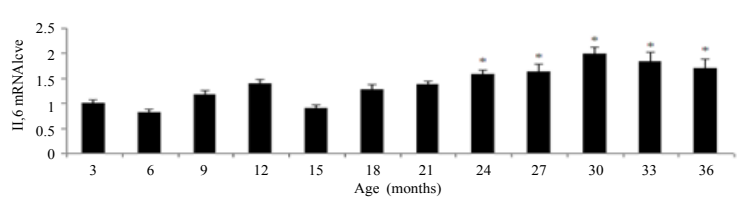

Figure 3B: The relative mRNA levels of interleukin-6 (IL-6) using real-time RT-PCR assay at the $\mathrm{CP}$ epithelium in normal aging rats

The measured quantity of mRNA in each of treated samples was normalized using CT values obtained for the $\beta$-actin mRNA amplifications running in the same plate. The data were the means \pm standard deviation of three sets of experiments

Graph of the log-transformed normalized expression of IL- 6 with age, $n=8$ for each age group tested. One-way ANOVA revealed an effect of age for the twelve tested age groups at the ${ }^{*} P<0.05$ level.

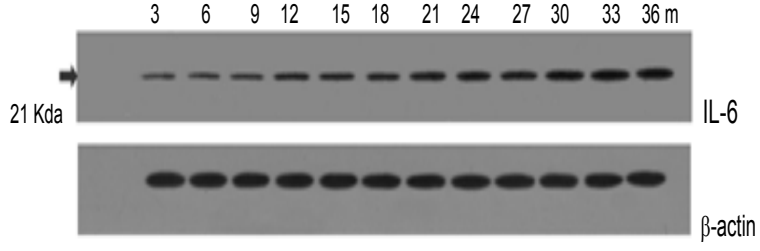

Figure 4A: Protein expression levels of interleukin-6 (IL-6) at the CP epithelium in normal aging rats

Immunoreactive proteins were detected by using the enhanced chemiluminescence method. It showed that there was a significant increase from 21 to $36 \mathrm{~m}$ group for the twelve aged groups, $n=8$ for each age group.

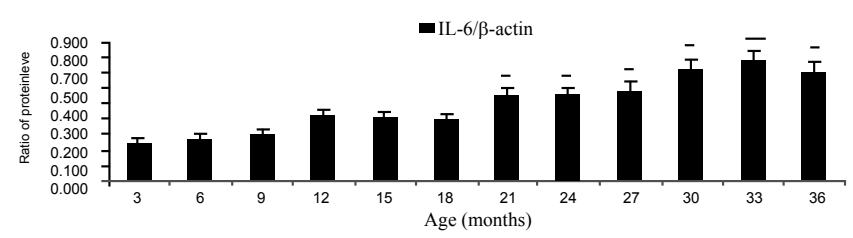

Figure 4B: The ratio of interleukin-6 (IL-6)/ $\beta$-actin protein levels at the CP epithelium in normal aging rats

The intensity of the specific bands was detected and analyzed by Odyssey infrared imaging system. IL-6 protein levels in each specimen were normalized to $\beta$-actin.

Graph of the relative protein levels expression of IL- 6 with age, $n=8$ for each age group tested. One-way ANOVA revealed an effect of age for the twelve tested age groups at the ${ }^{*} \mathrm{P}<0.05$ and ${ }^{* *} \mathrm{P}<0.01$ level.

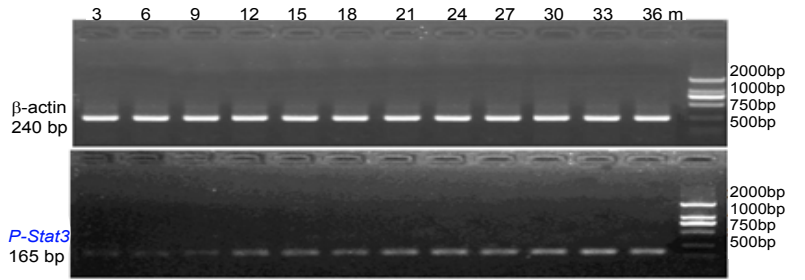

Figure 5A: mRNA expression levels of phosphorylated signal transduction and activators of transcription 3 (P-Stat3) at the CP epithelium in normal aging rats

For real time reverse transcription quantitative PCR ( $q P C R$ ), independent assays were performed using SYBR premix Ex TaqTM with three biological replicates. Gelred was added to the gel pre-run, the DNA band was visualized under UV light and was then extracted. It showed that there was a significant increase from 3 to $36 \mathrm{~m}$ group for the twelve aged groups, $\mathrm{n}=8$ for each age group

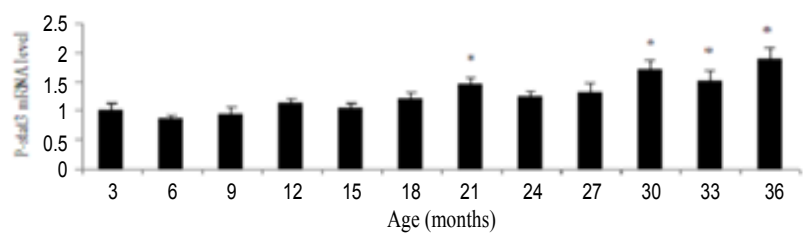

Figure 5B: The relative mRNA levels of phosphorylated signal transduction and activator of transcription 3 (P-Stat3) using real-time RT-PCR assay at the CP epithelium in normal aging rats

The measured quantity of mRNA in each of treated samples was normalized using CT values obtained for the $\beta$-actin mRNA amplifications running in the same plate. The data were the means \pm standard deviation of three sets of experiments.

Graph of the log-transformed normalized expression of P-Stat3 with age, $n=8$ for each age group tested. One-way ANOVA revealed an effect of age for the twelve tested age groups at the ${ }^{*} P<0.05$ level. 
Citation: Chongbin L, Rui W, Chunyan W, Chen HU, Qifeng D (2014) Altered Hepcidin Expression is Part of the Choroid Plexus Response to IL-6/ Stat3 Signaling Pathway in Normal Aging Rats. Bioenergetics 3: 115. doi:10.4172/2167-7662.1000115

Page 5 of 6

\section{Discussion}

In this work, a striking deterioration of the CP epithelial cells is observed in aged rats (Figure 1). These modifications could alter choroid plexus functions, including synthesis, secretion and transport of proteins and other molecules. There are also responsible for the deficits in molecular exchanges between the CP and the CSF. It likely lead not only to abnormal brain $A \beta$ clearance at the BCSFB, but also to the development of $A \beta$ accumulation in this tissue. These results are in accordance with previous finding $[3,16]$ in AD model rats.

In this study, in normal aging rats, we firstly found that there was a mild increase in Hamp expression at the CP from 3 to $18 \mathrm{~m}$ group rats, followed by a significant increase to $36 \mathrm{~m}$ group rats (Figure 2 ). Hepcidin is now regarded as the central regulator of body iron homeostasis $[17,18]$. Hepcidin also binds to the iron exporter Ferroportin-1 (FPN1), induces its internalization and degradation, and thereby blocks cellular iron efflux from neurons. Additionally, FPN1 is also found in the brain, mainly in the $\mathrm{CP}$, in the ependymal cells lining the ventricles, and in neuromelanin cells in the substantia nigra [19]. In this study, we also found that there was a mild increase in IL-6 expression at the CP from 3 to $21 \mathrm{~m}$ group rats, followed by a significant increase to $30 \mathrm{~m}$ group rats (Figures 3 and 4). Silvestri, et al. [20] showed that the proximal $165 \mathrm{bp}$ of the hepcidin promoter was critical for hepcidin activation in response to exogenously administered IL-6. High expression of the IL- 6 may be involved in iron deprivation during infection and inflammation, through hepcidin induction and FPN1 down regulation. With advancing aging, microglia are activated to a reactive phenotype

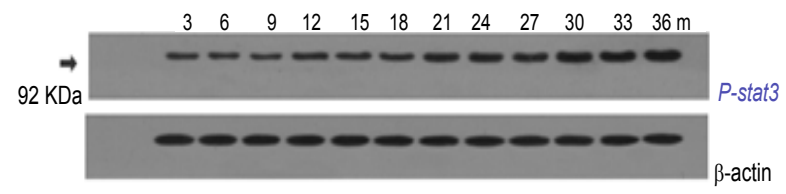

Figure 6A: Protein expression levels of phosphorylated signal transduction and activators of transcription 3 (P-Stat3) at the CP epithelium in normal aging rats

Immunoreactive proteins were detected by using the enhanced chemiluminescence method. It showed that there was a significant increase from 21 to $36 \mathrm{~m}$ group for the twelve aged groups, $n=8$ for each age group.

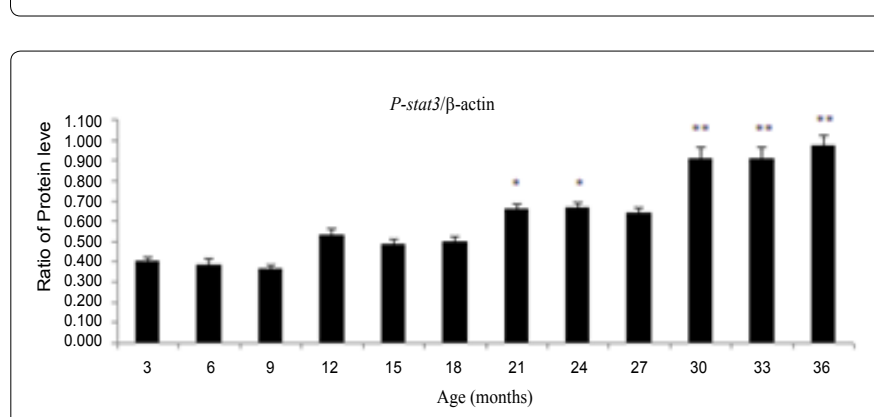

Figure 6B: The ratio of phosphorylated signal transduction and activators of transcription 3 (P-Stat3)/ $\beta$-actin protein levels at the CP epithelium in normal aging rats

The intensity of the specific bands was detected and analyzed by Odyssey infrared imaging system. P-Stat3 protein levels in each specimen were normalized to $\beta$-actin.

Graph of the relative protein levels expression of P-Stat 3 with age, $n=8$ for each age group tested. One-way ANOVA revealed an effect of age for the twelve tested age groups at the ${ }^{*} P<0.05$ and ${ }^{* *} P<0.01$ level. and release cytotoxic pro-inflammatory molecules including oxygen radicals, NO, glutamate, cytokines and prostaglandins, which can have a detrimental effect on other brain cells. In preliminary studies, it has shown that transferrin receptor 1 (Tfr1) and FPN1 were significantly downregulated in response to LPS treatment, while the divalent metal ion transporter (DMT1) and Hamp showed no change in expression under control conditions and after LPS treatment in N9 microglia cells [21]. This might suggest that iron homoeostasis is under the control of alternative mechanisms in microglia, for instance cytokines such as IL-6. Whether iron accumulates in activated microglia (which could explain the association between increased iron stores and microglia activation in specific brain regions of $\mathrm{AD}$ ) remains unknown. In this study, we firstly found that $P$-Stat 3 expression at the CP increased with age at the mRNA and protein levels (Figures 5 and 6). In normal aging, CP proteins will activate IL-6/Stat 3 cell signal transduction pathway to alter transcriptin of Hamp, the gene which encodes hepcidin. In previous studies, it has shown that IL-6 regulated Hamp expression in the liver, upon interaction with the cognate cellular receptor, and through the Stat 3 signaling transduction pathway [9,22-25]. We think that the same mechanism seems to be operational at the CP. Therefore, Stat3 is a key effector of baseline Hamp expression as well as during inflammatory conditions. Because the $\mathrm{CP}$ is composed not only of epithelial cells but also of a stroma containing endothelial cells of blood vessels and eventually immune cells, we next asked if epithelial cells of the $\mathrm{CP}$ were responsible for up-regulating the expression of genes endoding for Hamp and other iron-related genes.

\section{Acknowledgments}

The authors thank all reviewers and Prof. P.H. Backx (University of Toronto, Canada) and Prof. Z.M. Qian (The Hong Kong Polytechnic University, China) for critical reading. We are grateful to the Zhejiang Province Natural Sciences Foundation (Y2110388) and Zhejiang Province Technological Research (Y2011C37091) for financial support.

\section{References}

1. Hardy J (2006) A hundred years of Alzheimer's disease research. Neuron 52 3-13.

2. Querfurth HW, LaFerla FM (2010) Alzheimer's disease. N Engl J Med 362 329-344.

3. Bush Al (2013) The metal theory of Alzheimer's disease. J Alzheimers Dis 33 Suppl 1: S277-281.

4. Wang L, Xi G, Keep RF, Hua Y (2012) Iron enhances the neurotoxicity of amyloid $\hat{I}^{2}$. Transl Stroke Res 3: 107-113.

5. Mawuenyega KG, Sigurdson W, Ovod V, Munselli T, Kasten T, et al. (2010) Decreased clearance of CNS ß-Amyloid in Alzheimer's disease. Science 330 1774.

6. Silverberg GD, Miller MC, Messier AA, Majmudar S, Machan JT, et al. (2010) Amyloid deposition and influx transporter expression at the blood-brain barrier increase in normal aging. J Neuropathol Exp Neurol 69: 98-108.

7. Serot JM, Zmudka J, Jouanny P (2012) A possible role for CSF turnover and choroid plexus in the pathogenesis of late onset Alzheimer's disease. $J$ Alzheimers Dis 30: 17-26.

8. Marques F, Sousa JC, Correia-Neves M, Oliveira P, Sousa N, et al. (2007) The choroid plexus response to peripheral inflammatory stimulus. Neuroscience 144: 424-430.

9. Marques F, Falcao AM, Sousa JC, Coppola G, Geschwind D, et al. (2009) Altered iron metabolism is part of the choroid plexus response to peripheral inflammation. Endocrinology 150: 2822-2828.

10. Chen J, Buchanan JB, Sparkman NL, Godbout JP, Freund GG, et al. (2008) Neuroinflammation and disruption in working memory in aged mice after acute stimulation of the peripheral innate immune system. Brain Behav Immun 22: 301-311.

11. Villeda SA, Luo J, Mosher KI, Zou B, Britschgi M, et al. (2011) The ageing 
Citation: Chongbin L, Rui W, Chunyan W, Chen HU, Qifeng D (2014) Altered Hepcidin Expression is Part of the Choroid Plexus Response to IL-6/ Stat3 Signaling Pathway in Normal Aging Rats. Bioenergetics 3: 115. doi:10.4172/2167-7662.1000115

systemic milieu negatively regulates neurogenesis and cognitive function. Nature 477: 90-94.

12. Ferrucci L, Semba RD, Guralnik JM, Ershler WB, Bandinelli S, et al. (2010) Proinflammatory state, hepcidin, and anemia in older persons. Blood 115 3810-3816.

13. Lee P, Peng H, Gelbart T, Wang L, Beutler E (2005) Regulation of hepcidin transcription by interleukin-1 and interleukin-6. Proc Natl Acad Sci U S A 102: 1906-1910.

14. Schmittgen TD, Livak KJ (2008) Analyzing real-time PCR data by the comparative C(T) method. Nat Protoc 3: 1101-1108.

15. Ke Y, Chen YY, Chang YZ, Duan XL, Ho KP, et al. (2003) Post-transcriptional expression of DMT1 in the heart of rat. J Cell Physiol 196: 124-130.

16. Johansson PA, Dziegielewska KM, Liddelow SA, Saunders NR (2008) The blood-CSF barrier explained: when development is not immaturity. Bioessays 30: $237-248$

17. Darshan D, Anderson GJ (2009) Interacting signals in the control of hepcidin expression. Biometals 22: 77-87.

18. Ganz T, Nemeth E (2011) Hepcidin and disorders of iron metabolism. Annu Rev Med 62: 347-360.

19. Clardy SL, Wang X, Boyer PJ, Earley CJ, Allen RP, et al. (2006) Is ferroportinhepcidin signaling altered in restless legs syndrome? J Neurol Sci 247: 173179 .
20. Silvestri L, Pagani A, Camaschella C (2008) Furin-mediated release of soluble hemojuvelin: a new link between hypoxia and iron homeostasis. Blood 111 924-931.

21. Ward RJ, Crichton RR, Taylor DL, Della Corte L, Srai SK, et al. (2011) Iron and the immune system. J Neural Transm 118: 315-328.

22. Stoian I, Manolescu B, Atanasiu V, Lupescu O, BuÅŸu C (2007) IL-6 - STAT3 - hepcidin: linking inflammation to the iron metabolism. Rom J Intern Med 45: 305-309.

23. Sakamori R, Takehara T, Tatsumi T, Shigekawa M, Hikita H, et al. (2010) STAT3 signaling within hepatocytes is required for anemia of inflammation in vivo. J Gastroenterol 45: 244-248.

24. Armitage AE, Eddowes LA, Gileadi U, Cole S, Spottiswoode N, et al. (2011) Hepcidin regulation by innate immune and infectious stimuli. Blood 118: 4129 4139.

25. Pagani A, Nai A, Corna G, Bosurgi L, Rovere-Querini P, et al. (2011) Low hepcidin accounts for the proinflammatory status associated with iron deficiency. Blood 118: 736-746. 